\title{
Study of endometrial lesions in patients presenting with abnormal uterine bleeding to a Medical College Hospital
}

\author{
Bhowmik S.R. ${ }^{1}$, Singh R. ${ }^{2}$, P.K. Lal ${ }^{3}$ \\ ${ }^{1}$ Dr. Samir Ranjan Bhowmik, Assistant Professor, Department of Pathology, Gouri Devi Institute of Medical Sciences, \\ Rajbandh, Durgapur, West Bengal, ${ }^{2}$ Dr. Ramanuj Singh, Associate Professor, Department of Anatomy, ANMMCH, Gaya, \\ Bihar, ${ }^{3}$ Dr. Prabhat Kumar Lal, Associate Professor, Department of PSM, Darbhanga Medical College, Darbhanga, Bihar, \\ India.
}

Corresponding Author: Dr. Ramanuj Singh, Associate Professor, Department of Anatomy, ANMMCH, Gaya, Bihar, India. Email: ramanujsingh882@gmail.com

\begin{abstract}
Introduction: Abnormal uterine bleeding is common presentation in gynaecological OPD. Endometrial biopsy is helpful in proper diagnosis and ruling out malignancy. Methods: The present study was cross-sectional in nature conducted upon 164 endometrial specimens of patients suffering from abnormal uterine bleeding to assess the histopathological profile. Profile of patients, symptoms and histopathological findings were noted. Results: 41-50 years was the most common age group (32.9\%). Most common bleeding pattern observed was menorrhagia (26.8\%) followed by metrorrhagia (25\%). The most common histopathological finding was proliferative phase $(25.6 \%)$ followed by secretory phase $(22.6 \%)$. Polyp was present in $7.3 \%$ cases and endometrial carcinoma was observed in $2.4 \%$ cases. Conclusion: Histopathological assessment of endometrial specimen is helpful in diagnosis in these cases.
\end{abstract}

Key words: Abnormal Uterine Bleeding, Endometrial lesions, Histopathology, Cross-sectional study

\section{Introduction}

Abnormal uterine bleeding (AUB) has been defined as any uterine bleeding that differs in frequency, pattern or amount from normal menstrual cycle or post-menopausal bleeding. The irregular pattern is irregular of prolonged duration in individual cycle lengths over a period of 1 year or heavy menstrual bleeding are considered to be abnormal [1]. A classification system (PALM-COEIN) for causes of the AUB in non-gravid women of reproductive age has been proposed by International Federation of Gynaecology and Obstetrics working group on menstrual disorder.

The nine main categories include Polyp; adenomyosis; leiomyoma; malignancy and hyperplasia; coagulopathy; ovulatory dysfunction; endometritis; iatrogenic; and not yet classified fairly represent the acronym PALMCOEIN [2]. The bleeding may be caused by organic disease like endometrial polyp, endometrial hyperplasia, chronic endometritis, complications of pregnancy and endometrial malignancies. The functional causes include normal endometrium and abnormal physiological endometrium which includes atrophic endometrium,

Manuscript received: $14^{\text {th }}$ May 2019

Reviewed: $24^{\text {th }}$ May 2019

Author Corrected: $30^{\text {th }}$ May 2019

Accepted for Publication: $4^{\text {th }}$ June 2019 weakly proliferative and disordered proliferative endometrium [3]. AUB is one of the common causes of gynaecological consultation. $30 \%$ of all patient consultations in the reproductive age group and $5 \%$ in post-menopausal groups are related to this condition [4]. The bleeding patterns are identified as menorrhagia, metrorrhagia, oligomenorrhea, polymenorrhoea and dysfunctional uterine bleeding [5].

Histopathological examination of endometrium is helpful in identifying the organic causes as well as in assessing the endometrial pattern. Cytological studies include brush or jet washing and suction and curettage. Endometrial biopsy is safe and effective to identify the organic causes. Endometrial biopsy has very high sensitivity of $96 \%$ for the detection of endometrial abnormalities [6].

It assists in early diagnosis of endometrial carcinoma and to find the onset of atypical hyperplasia. The identification of spectrum of lesions in different groups can be helpful in clinical management of cases. Very few studies have been done to find the histopathology in cases of abnormal uterine bleeding in this area. Hence, this study was proposed. 
Aims \& objectives- The present study was undertaken to assess the histopathological findings of endometrial lesions seen in patients suffering from abnormal uterine bleeding.

\section{Material and Methods}

Study setting: The present study was cross-sectional in nature conducted at the department of Pathology, Gouri Devi Institute of Medical Sciences, Rajbandh, Durgapur.This is a tertiary level health hospital. Patients from nearby districts of West Bengal and adjoining area of Jharkhand come to this institute for treatment. Hence, we have patients from varying background and culture.

Duration and type of study: The present study was cross-sectional in nature conducted between April 2018 to May 2019. Data collection was done between May 2018 to April 2019.

Study subjects: Study subjects included patients reporting to the Gynaecology OPD of the institute and suffering from abnormal uterine bleeding from whom endometrial specimen was taken.

Inclusion criteria: Patients above 18 years of age suffering from uterine bleeding were included in the present study.

Exclusion criteria: Those patients who did not give consent for the study, who had isolated causes of uterine bleeding including leiomyoma, bleeding disorders and cervical or vaginal pathology.

Sample size calculation: Iqbal et al found in their study that $43.7 \%$ of the endometrial specimen were abnormal. Considering $\mathrm{p}=0.437, \mathrm{q}=0.563, \mathrm{Z}=1.96$ for confidence level of $95 \%$ and $d$ (relative precision $)=0.2$, sample size was calculated to be 149 . Considering non-response rate of $10 \%$, final sample size was 164 . Thus, a total of 164 patients were studied.

\section{Original Research Article}

Sampling methods: Sampling was purposive in nature and the patients who fulfilled the selection criteria were sequentially included in the present study till the desired sample size was achieved.

Data collection procedure: Head of the department of obstetrics and gynaecology was informed about the protocol and importance of this study and was taken into confidence. The patients were selected on the basis of referral slip received in the department of Pathology. The patients were visited in the wards and consent was taken from them. Case history of patients were evaluated to note their background profile and clinical history. Findings of general and systemic examination as well as reports of other investigations were noted. Samples of endometrium were received in the department of Pathology.

It was processed and fixed in 10\% formalin. Multiple sections of $5 \mu$ thickness were taken from formalin fixed paraffin embedded tissue blocks. Staining was done by haematoxylin and eosin (H\&E) stain. The slides were examined microscopically and histopathological changes were noted.

Data analysis: Pre-tested proforma was used for data collection. It was entered into Microsoft Excel 2003 and analysed using Statistical Package for Social Sciences (SPSS) v 16.0. Categorical data were represented as frequency and percentage and numerical data as mean and standard deviation. Appropriate statistical tests were done when needed.

Ethical consideration \& permission: Permission was obtained from Institutional Ethics Committee for the study. All the study subjects were informed about the study and consent was taken from them. Those who did not give consent were not included. Confidentiality of records was maintained.

\section{Results}

A total of 164 endometrial biopsy were included in the present study. Table-1 shows the age distribution of the patients. Majority of the patients belonged to the age group of 41-50 years (32.9\%) followed by 31-40 years (31.1\%). 20.8\% patients were above 50 years of age.

Table-1: Age distribution of patients.

\begin{tabular}{|c|c|c|}
\hline Age (in years) & Frequency $(\mathbf{n = 1 6 4 )}$ & \% \\
\hline$<30$ & 25 & 15.2 \\
\hline $31-40$ & 51 & 31.1 \\
\hline $41-50$ & 54 & 32.9 \\
\hline $51-60$ & 26 & 15.9 \\
\hline$>60$ & 8 & 4.9 \\
\hline Total & $\mathbf{1 6 4}$ & $\mathbf{1 0 0}$ \\
\hline
\end{tabular}

Pathology Update: Tropical Journal of Pathology \& Microbiology Available online at: www.medresearch.in 674 | P a g e 


\section{Original Research Article}

Table-2 and chart-1 show the clinical pattern of bleeding. Most common pattern observed was menorrhagia (26.8\%) followed by metrorrhagia ( $25 \%)$, continuous bleeding $(18.9 \%)$ and polymenorrhea (18.3\%). Post-menopausal bleeding was seen in $11 \%$ patients.

Table-2: Clinical pattern of bleeding

\begin{tabular}{|c|c|c|}
\hline Clinical pattern & Frequency $(\mathbf{n = 1 6 4 )}$ & $\mathbf{\%}$ \\
\hline Menorrhagia & 44 & 26.8 \\
\hline Metrorrhagia & 41 & 25 \\
\hline Polymenorrhea & 30 & 18.3 \\
\hline Post-menopausal bleeding & 18 & 11 \\
\hline Continuous & 31 & 18.9 \\
\hline Total & $\mathbf{1 6 4}$ & $\mathbf{1 0 0}$ \\
\hline
\end{tabular}

Table- 3 and chart-2 show the findings of histopathological examination. It was seen that proliferative phase was the most common histopathological finding $(25.6 \%)$ followed by secretory phase $(22.6 \%)$, other patterns $(21.3 \%)$ and simple hyperplasia (10.4\%). Polyp was seen in $7.3 \%$ cases and endometrial carcinoma was observed in $2.4 \%$ cases. While proliferative phase, secretory phase and endometritis were common findings in those $<40$ years, complex hyperplasia, polyp and carcinoma were common in those above 50 years of age.

Table-3: Histopathological findings among the cases

\begin{tabular}{|l|c|c|c|c|}
\hline Histopathological findings & $<\mathbf{4 0}$ years & $\mathbf{4 1 - 5 0}$ years & $>\mathbf{5 0}$ years & Total \\
\hline Proliferative phase & $19(45.2 \%)$ & $16(38.1 \%)$ & $7(16.7 \%)$ & 42 \\
\hline Secretory phase & $27(73 \%)$ & $9(24.3 \%)$ & $1(2.7 \%)$ & 37 \\
\hline Simple Hyperplasia & $5(29.4 \%)$ & $9(52.9 \%)$ & $3(17.6 \%)$ & 17 \\
\hline Complex hyperplasia & $2(28.6 \%)$ & $1(14.3 \%)$ & $4(57.1 \%)$ & 7 \\
\hline Endometritis & $9(90 \%)$ & $1(10 \%)$ & $0(0 \%)$ & 10 \\
\hline Polyp & $3(25 \%)$ & $3(25 \%)$ & $6(50 \%)$ & 12 \\
\hline Carcinoma & $0(0 \%)$ & $1(25 \%)$ & $3(75 \%)$ & 4 \\
\hline Others & $11(31.4 \%)$ & $14(40 \%)$ & $10(28.6 \%)$ & 35 \\
\hline Total & $\mathbf{7 6 ( 4 6 . 3 \% )}$ & $\mathbf{5 4}(\mathbf{3 2 . 9} \%)$ & $\mathbf{3 4}(\mathbf{2 0 . 7} \%)$ & $\mathbf{1 6 4}$ \\
\hline
\end{tabular}

\section{Discussion}

Any bleeding pattern that deviates from normal menstrual bleeding is included in abnormal uterine bleeding [7]. It may be due to organic and non-organic causes. Organic causes include diseases of reproductive tract and systemic diseases. If an organic cause cannot be ascertained, the bleeding is termed as dysfunctional uterine bleeding. It is a diagnosis of exclusion and is due to functional derangements. Notable among these is high levels of oestrogen [8].

The etiology of abnormal uterine bleeding has been explored by many researchers. In the present study, 164 cases were included. It was seen that majority of the patients belonged to the age group of 41-50 years $(32.9 \%)$ followed by $31-40$ years $(31.1 \%)$. While

dysfunctional uterine bleeding is more common in younger age groups, the organic causes predominate in the older ones. Iqbal et al also found that most patients belonged to the perimenopausal age group i.e. between 40-50 years followed by the reproductive age group $<40$ years and then the postmenopausal age group $>50$ years [9]. Cornitesc et al found in perimenopausal patients that $35.5 \%$ of them belonged to the age group of $41-45$ years and $64.5 \%$ to the age group of $46-52$ years [10]. Singh et al reported that the age group of the patients ranged from 21 years to 70 years and included both reproductive and 


\section{Original Research Article}

postmenopausal age group patients. Maximum number of cases were seen in the age group of 41 to 50 years [11]. Parmar et al found that the age of patients with abnormal uterine bleeding ranged from 20-70 years and the most common age group was $40-50$ years [12]. Shajitha et al included 50 cases in the age group of $40-51$ years. $62 \%$ of patients belong to the age group $40-45$ years. $34 \%$ of patients correspond to age group 46-49 years [13]. Saraswathi et al found that age of patients with AUB ranged from 17 to 79 years. Abnormal uterine bleeding was commonly seen in 41 to 50 years age group [14].

The observation of the clinical pattern of bleeding in the present study indicated that menorrhagia was the most common pattern $(26.8 \%)$ followed by metrorrhagia $(25 \%)$, continuous bleeding $(18.9 \%)$ and polymenorrhea (18.3\%). Post-menopausal bleeding was seen in $11 \%$ patients. Iqbal et al found that maximum numbers of patients presented with menorrhagia (36\%) followed by polymenorrhoea $(20.40 \%)$. Postmenopausal bleeding, metrorrhagia and oligomenorrhoea were seen in $17.1 \%$, $16.70 \%$ and $6.0 \%$ respectively [9]. Shajitha et al reported that menorrhagia was the most common bleeding pattern followed by polymenorrhagia [13].

The findings of histopathological examination indicated that proliferative phase was the most common observation (25.6\%) followed by secretory phase (22.6\%), other patterns $(21.3 \%)$ and simple hyperplasia (10.4\%). Polyp was seen in $7.3 \%$ cases and endometrial carcinoma was observed in $2.4 \%$ cases. Proliferative phase, secretory phase and endometritis were common findings in those $<40$ years, complex hyperplasia, polyp and carcinoma were common in those above 50 years of age. Proliferative phase is related to high levels of oestrogen in blood. The hormonal imbalance is responsible in a quarter of cases. Endometrial hyperplasia is common finding in perimenopausal women. Sustained level of oestrogens results in epithelial overgrowth affecting glands and stroma and abnormal vascularization. Large amount of hyperplastic tissue and random breakdown of tissue resulting in exposure of vascular channels are responsible for irregular or prolonged bleeding due to anovulatory cycles [9].

Iqbal et al found that normal histopathological pattern was observed in $48.3 \%$ cases, out of which $28.1 \%$ cases showed proliferative phase endometrium whereas in $20.2 \%$ cases, secretory phase was noted. In $14.7 \%$ cases, hyperplastic endometrium was observed. Among the hyperplastic cases, $10.8 \%$ were simple and complex in the remaining 3.9\% cases. Exogenous hormonal effect was seen in $14.8 \%$ cases. Endometrial carcinoma was seen in $2.3 \%$ cases. In $<40$ years age group, secretory phase was observed in $32.5 \%$ cases whereas proliferative phase was seen in $27 \%$ of cases. In $40-50$ years, age group, the most frequent pattern observed was proliferative $(28.06 \%)$ followed by exogenous hormonal effect in $20.5 \%$. In $>50$ years age group, atrophic endometrium was seen in $28.9 \%$ followed by proliferative phase in $18.18 \%$. Carcinoma was reported in $6.25 \%$ cases [9]. Singh et al found that the predominant histopathological pattern was proliferative endometrium (18\%). Second commonest cause was uterine leiomyoma (16.4\%).

Adenomyosis and chronic endometritis accounted for $12 \%$ of cases each. Complications of pregnancy were seen in $10.4 \%$ cases in which retained products of conception was the predominant cause followed by ectopic gestation, partial and complete mole [11]. Parmar et al observed that the predominant pattern was of normal cyclical endometrium (32.35\%), followed by disordered (cystic, glandular or cystic-glandular) proliferative endometrium(33.33\%).Benign endometrial polyp was observed in $10.78 \%$ cases, pregnancy associated conditions in $0.08 \%$ cases and endometrial hyperplasia without atypia in $0.05 \%$ cases [12]. Shajitha et al found that most common type of endometrial pattern was proliferative endometrium. $60 \%$ of cases had proliferative type of endometrium, $20 \%$ had secretary pattern, $8 \%$ had irregular shedding, $1 \%$ had cystoglandular hyperplasia, $3 \%$ had simple hyperplasia and $1 \%$ women had adenocarcinoma [13].

Saraswathi et al examined 620 patients and commented that histopathologic examination showed various pattern in AUB consisting of normal cyclical pattern showing proliferative, secretory and shedding phases in 116 patients. Hyperplasia was observed in 25 patients of which 8 patients presented with atypia. Chronic endometritis was seen in 17 patients, including one case of tuberculous endometritis. Complications of pregnancy were seen in 93 cases with abortion being the predominant cause (80 cases) [14].

Major association of bleeding in this study was found to be with normal physiologic phases such as proliferative, secretory and atrophic menstrual pattern. Organic causes were also important which need proper exploration.

\section{Conclusion}

It is concluded from the present study that the causes of abnormal uterine bleeding vary in different age groups. diagnostic tool for assessment of abnormal uterine bleeding,histopathological examination of endometrium is gold standard. In most of cases with AUB, benign lesions of endometrium are responsible. However, perimenopausal age group cases need careful evaluation. 


\section{What the study adds to the existing knowledge?}

Though abnormal uterine bleeding is a common condition, very few literatures regarding its causes and pattern in this place has been published. The present study tried to fill the gap and generate evidence regarding the same.This will help in proper intervention and reduction in morbidity and mortality related to this condition.

\section{Author contribution:}

Dr. Samir Ranjan Bhowmik: Design of the study and data collection.

Dr Ramanuj Singh: Review of the article and proof reading.

Dr Prabhat Kumar Lal: Data analysis and finalization of the draft.

Findings: Nil; Conflict of Interest: None initiated Permission from IRB: Yes

\section{References}

1. Sharma R, Mishra P, Kumar N, Srivastava P. Histomorphological spectrum of endometrial lesion in women presenting with abnormal uterine bleeding: A 3year study at a tertiary care center. Trop J Path Micro 2018;4(7):525- 531.doi:10.17511/ jopm. 2018.i7.08.

2. Munro MG, Critchley HO, Broder MS, et al. FIGO classification system (PALM-COEIN) for causes of abnormal uterine bleeding in nongravid women of reproductive age. Int J Gynaecol Obstet. 2011;113 (1): 313.doi:10.1016/j.ijgo.2010.11.011. Epub 2011 Feb 22

3. Padubidri VG, Daftary SN. Howkins and Bourne Shaw's textbook of gynaecology. $16^{\text {th }}$ ed. Elsevier;2015: 321-322.

4. Moodley M, Roberts C. Clinical pathway for the evaluation of postmenopausal bleeding with an emphasis on endometrial cancer detection. J Obstet Gynaecol. 2004; 24 (7):736-741. doi: https://doi.org/10. $1080 / 014436104100009394$

5. Goodman A. Abnormal genital tract bleeding. Clin Cornerstone. 2000;3(1):25-35. doi: https://doi.org/10. 1016/ S1098-3597(00)90019-X
6. Khare A, Bansal R, Sharma P, Ehlence N. Morphological spectrum of endometrium in patients presenting with dysfunctional uterine bleeding. People's J Res. 2012;5(2):13-16.

7. Ely JW, Kennedy CM, Clark EC, Bowdler NC. Abnormal Uterine Bleeding: A Management Algorithm. J Am Board Fam Med. 2006;19(6):590-602. doi: https://doi.org/10.3122/jabfm.19.6.590

8. Litta P, Merlin F, Saccardi C, Pozzan C, Sacco G, Fracas $\mathrm{M}$ et al. Role of hysteroscopy with endometrial biopsy to rule out endometrial cancer in postmen-opausal women with abnormal uterine bleeding. Maturitas 2005; 50(2):117-123. doi: https://doi. org/ 10. 1016/j.maturitas.2004.05.003

9. Iqbal MB, Kambale T, Khandelwal A, Koshy A, Banerjee B. Spectrum of Endometrial lesions in patients presenting with abnormal uterine bleeding. Indian $\mathrm{J}$ Pathol Oncol. 2018;5(4):587-591. doi: 10.18231/23946792.2018.0113.

10. Cornitescu F, Tanase F, Simionescu C, Illiescu D. Clinical, histopathological and therapeutic considerations in non-neoplastic abnormal uterine bleeding in menopause transition. Rom J Morphol Embryol. 2011; 52(3):759-765.

11. Singh S, Pandey P, Agarwal S, Kaur S, Singh S. Spectrum of uterine lesions presenting as abnormal uterine bleeding in a rural north Indian population: a study from tertiary care center. Int J Res Med Sci. 2016; 4(8):3250-3254. http://dx.doi.org/10.18203/2320-6012. ijrms 20162274 .

12. Parmar J, Desai D. Study of endometrial pathology in abnormal uterine bleeding. Int J Reprod Contracept Obstet Gynecol. 2013;2(2):182-185. doi: 10.5455/23201770.ijrcog20130614.

13. Shajitha S., Sangeereni M, Mallika A. Study of endometrial pathology in abnormal uterine bleeding. In J Curr Med Sci. 2017;7(10):324-326. doi: http://dx.doi. org/10.24327/ijcmes2017.07100025.

14. Saraswathi D, Thanka J, Shalinee R, Aarthi R, Jaya V, Kumar PV. Study of Endometrial Pathology in Abnormal Uterine Bleeding. J Obstet Gynecol India. 2011;61(4):426-443. doi 10.1007/s13224-011-0047-2.

\section{How to cite this article?}

Bhowmik S.R., Singh R, P.K. Lal. Study of endometrial lesions in patients presenting with abnormal uterine bleeding to a Medical College Hospital. Trop J Path Micro 2019;5(9):673-677.doi:10.17511/jopm.2019.i09.09. 